\title{
DOES ADMINISTERING A PARENT REPORTED OUTCOME MEASURE DURING THE ANNUAL REVIEW PROCESS IMPROVE THE SELF-EFFICACY OF CARERS OF CHILDREN WITH CYSTIC FIBROSIS
}

\author{
T. Patel ${ }^{1}$, L. Patel ${ }^{1}$, C. Dixon ${ }^{1,2}$, C. Glasscoe ${ }^{1,2}$, K.W. Southern ${ }^{1,2}$ \\ ${ }^{1}$ University of Liverpool, ${ }^{2}$ Department of Women's and Children's Health, Institute of Translational \\ Medicine, Liverpool, UK
}

Background and aims: Cystic fibrosis (CF) is the most common life limiting, inherited disease to affect the Caucasian population. Medical advances have resulted in a longer life expectancy, at the expense of an intensive and often time-consuming treatment regime for patients. Children with CF rely on their primary care givers for adequate treatment. The 'Challenges of Living with Cystic Fibrosis Questionnaire' (CLCF-Q) has been developed as a tool to measure the burden of caring for a child with CF. The aim of this study is to identify whether the self-efficacy, as measured by the 'Cystic Fibrosis Self-Efficacy Questionnaire' (CFSEQ), can be improved by administering the CLCF-Q to the carer during the child's annual review.

Methods: This is a single centre, randomised control trial. Participants randomised to Group1 (intervention group) receive the CLCF-Q during the annual review. Group 2 is the control group. Those in Group 1 receive feedback based on their answers from the CLCF-Q. All participants complete the CFSE-Q at the beginning and end of the study (Phase I and Phase II respectively).

Results: Interim analysis demonstrates that participants in Group $1(\mathrm{n}=11)$ have a significantly greater improvement in their self-efficacy scores than Group 2 participants $(\mathrm{n}=15)$, at the end of phase II of the trial (Median (IQR) change in self-efficacy score 1 ( -1 to 4 ) versus -2 (-4 to 1$) ; U=41.000, \mathrm{p}=0.031$ ).

Conclusions: This study suggests that self-efficacy in carers of children with CF can be improved by administering and giving feedback on the CLCF-Q. 